\title{
Sperm-associated antigen 9 is upregulated in hepatocellular carcinoma tissue and enhances QGY cell proliferation and invasion in vitro
}

\author{
BIQIONG REN ${ }^{1-3}$, GUOYING ZOU ${ }^{1-3}$, JUNYU HE $^{1-3}$, YIRAN HUANG $^{2}$, \\ GUOAN MA ${ }^{3,4}$, GUOFENG XU ${ }^{1,2}$, YONG LI ${ }^{1,2}$ and PING YU ${ }^{3}$
}

\begin{abstract}
${ }^{1}$ Department of Clinical Laboratory, Hunan Provincial Second People's Hospital; ${ }^{2}$ Clinical Medical School, Hunan University of Chinese Medicine, Changsha, Hunan 410007; ${ }^{3}$ Department of Immunology, School of Basic Medicine, Central South University, Changsha, Hunan 410078; ${ }^{4}$ Department of Hepatobiliary Disease, Tumor Hospital of Hunan Province, Changsha, Hunan 410008, P.R. China
\end{abstract}

Received November 7, 2015; Accepted April 21, 2017

DOI: $10.3892 / \mathrm{ol} .2017 .7270$

\begin{abstract}
The incidence and mortality rates of hepatocellular carcinoma (HCC) are higher in China compared with in other countries. Further research is required in order to improve the diagnosis and treatment of HCC. Sperm-associated antigen 9 (SPAG9) protein has been revealed to serve an important function in cancer progression; however, the underlying mechanisms remain to be elucidated. The present study investigated the expression level of SPAG9 in HCC tissues using quantitative-polymerase chain reaction, immunohistochemistry and western blotting, and the results demonstrated that SPAG9 was overexpressed in HCC tissues compared with the adjacent non-cancerous tissues. To explore the potential mechanisms underlying SPAG9 in HCC, the effect of SPAG9 on cell proliferation, cell cycle, migration and invasion capacities were investigated in the QGY HCC cell line by RNA interference. It was revealed that inhibition of SPAG9 mRNA in QGY cells significantly inhibited the expression level of SPAG9 compared with the control. Depletion of SPAG9 expression decreased cell proliferation $(P<0.01)$ and increased the percentage of cells in the $G_{1} / G_{2}$ cell cycle phase. The percentage of cells in the $\mathrm{S}$ phase was decreased, and cell migration and invasion capabilities in vitro were reduced $(\mathrm{P}<0.01)$. In summary, the results of the present study suggested that SPAG9 was upregulated in HCC and may serve an important function in cancer cell proliferation, differentiation and invasion. Whether SPAG9
\end{abstract}

Correspondence to: Professor Biqiong Ren, Department of Clinical Laboratory, Hunan Provincial Second People's Hospital, 427 Furong Road, Changsha, Hunan 410007, P.R. China

E-mail: 13808481211@163.com

Key words: hepatoma carcinoma, sperm-associated antigen 9, short interfering RNA, cell proliferation, cell cycle, cell migration is a potential diagnostic marker and therapeutic target of human HCC requires additional study.

\section{Introduction}

Sperm-associated antigen 9 (SPAG9) has characteristics of a scaffold protein and is involved in the c-Jun N-terminal kinase JNK signaling pathway, binding to JNK, which suggests that it is involved in physiological processes, including apoptosis, survival, proliferation and tumorigenesis $(1,2)$. SPAG9 is a member of the cancer/testis antigen family expressed from a single copy gene located on human chromosome 17q21. Proteins in the cancer/testis antigen family are overexpressed in a variety of types of cancer $(3,4)$. SPAG9 is also expressed in a variety of tumors (5-9). SPAG9 has been proposed as a novel biomarker for early diagnosis of multiple human tumors, including ovarian, cervical and breast cancers (10-12). Certain studies have revealed that small interfering RNA inhibits expression of SPAG9 and inhibits the growth of various types of tumor cells $(13,14)$. SPAG9 protein has been demonstrated to be involved in cancer progression; however, the underlying mechanisms remain unknown $(15,16)$.

Hepatocellular carcinoma (HCC) is the sixth most common type of cancer globally and is the third most common cause of cancer-associated mortality (17). The incidence of $\mathrm{HCC}$ is higher in South East Asia and Africa compared with other regions of the world (18). The crucial etiological factors involved in the development of HCC include infection with hepatitis virus, the structural or functional mutation of oncogenes and tumor suppressor genes (19-21). Long non-coding RNA URHC regulates cell proliferation and apoptosis by zinc-activated channels via the extracellular signal-related kinase/mitogen-activated protein kinase (MAPK) signaling pathway in HCC (22), and microRNA-24 may modify aflatoxin B1-related HCC prognosis and tumorigenesis (23). Therefore, it is necessary to further the research in this area in order to improve the diagnosis and treatment of HCC. In the present study, a series of methods were used to evaluate the expression 
level of SPAG9 in human HCC tumor tissue and its potential underlying mechanisms.

\section{Materials and methods}

Cell culture. The QGY human HCC cell line was purchased from Shanghai Institute of Pharmaceutical Industry (Shanghai, China) and cultured in RPMI-1640 (HyClone; GE Healthcare Life Sciences, Logan, UT, USA) supplemented with $10 \%$ fetal bovine serum (FBS; Gibco; Thermo Fisher Scientific, Inc., Waltham, MA, USA), $100 \mathrm{U} / \mathrm{ml}$ penicillin and $100 \mu \mathrm{g} / \mathrm{ml}$ streptomycin (GE Healthcare) at $37^{\circ} \mathrm{C}$ in the presence of $5 \%$ $\mathrm{CO}_{2}$

Patient samples. A total of $16 \mathrm{HCC}$ participants were enrolled between August 2010 and March 2013 at Xiangya Hospital, Central South University (Changsha, China). Written informed consent was obtained from all patients prior to enrollment in the present study. The exclusion criteria of the present study were as follows: i) Patients had distant metastasis; ii) Patients had received previous radiotherapy and chemotherapy prior to hepatectomy; iii) Patients with serious infection or other malignant diseases. The experimental protocols were approved by the Institutional Review Board of Xiangya Hospital. Carcinoma and adjacent noncancerous tissues were obtained from 16 patients with HCC during surgical tumor resections in accordance with informed consent. The present study was approved by the Ethics Committee of Hunan Provincial Second People's Hospital (Changsha, China). HCC was confirmed by pathobiology. All clinical and biological data are presented in Table I.

Total RNA extraction and reverse transcription-quantitative polymerase chain reaction $(R T-q P C R)$. Total RNA was extracted from HCC tissues and corresponding non-tumor normal tissues using TRIzol reagent (CWbio, Beijing, China) and cDNA synthesis was performed using the RevertAid First Strand cDNA Synthesis kit (CWbio), according to the manufacture's protocol. The qPCR was performed at $95^{\circ} \mathrm{C}$ for $10 \mathrm{~min}$, followed by 40 cycles at $95^{\circ} \mathrm{C}$ for $15 \mathrm{sec}$ and at $60^{\circ} \mathrm{C}$ for $60 \mathrm{sec}$ and qPCR was performed using GoTaq qPCR master mix (Promega Corporation, Madison, WI, USA); BRYT Green ${ }^{\circledR}$ dye was used in the GoTaq qPCR master mix. For detection of SPAG9 mRNA expression levels, GAPDH was amplified in parallel as an internal control. The sequences of the primers used for qPCR were as follows: SPAG9 forward, 5'-AGCCGA CTTTTCAGCTCCTC-3' and reverse, 5'-AAAGCCTGCACT CTACCGTC-3'; GAPDH forward, 5'-CAATGACCCCTTCAT TGACC-3' and reverse, 5'-GACAAGCTTCCCGTTCTCAG-3' and the temperature protocol of reverse transcription was $37^{\circ} \mathrm{C}$. The mRNA expression level was evaluated using evaluated threshold cycle $(\mathrm{Cq})$ values. The $\mathrm{Cq}$ values were normalized to the expression levels of GAPDH and the relative amount of mRNA specific to each of the target genes was determined using the $2^{-\Delta \Delta \mathrm{Cq}}$ method (18-22). qPCR was performed with the BIO-RAD CFK96 ${ }^{\mathrm{TM}}$ Real-Time System (Bio-Rad Laboratories, Inc., Hercules, CA, USA). The data were analyzed using BIO-RADCFK Manager 2.0 software (Bio-Rad Laboratories, Inc.) for 40 cycles. Experiments were performed in triplicate.
Immunohistochemistry (IHC) and evaluation of staining. IHC was performed using the peroxidase anti-peroxidase technique as follows: Slides were incubated in citrate buffer at $\mathrm{pH} 6$ and heated in a microwave for $21 \mathrm{~min}$ at $(200 \mathrm{~W})$. The antibody for SPAG9 was purchased from Abcam (cat. no. ab12331; Abcam, Cambridge, MA, USA). Antibody against SPAG9 (1:150; ab12331; Abcam) was overlaid on HCC and corresponding non-tumorous normal tissue sections $(4 \mu \mathrm{m})$ and incubated overnight at $4^{\circ} \mathrm{C}$. Secondary antibody incubation using alkaline phosphatase-conjugated mouse anti-rabbit immunoglobulin $\mathrm{G}$ (cat. no. sc-2358; 1:1,000; Santa Cruz Biotechnology, Inc., Dallas, TX, USA) was performed at room temperature for $30 \mathrm{~min}$.

Tissue sections were blindly evaluated by two pathologists from the Department of Pathology, Xiangya Hospital, Central South University (Changsha, China) in an effort to provide a consensus on staining patterns by light microscopy (magnification, x100; Olympus Corporation, Tokyo, Japan). SPAG9 staining was performed according to the methods described by Kanojia et al (23). Each case was rated according to a score that added a scale of intensity of staining to the area of staining. At least 10 high-power fields were chosen randomly and $>1,000$ cells were counted for each section. The intensity of staining was graded on the following scale: 0 , no staining; $1+$, mild staining; $2+$, moderate staining; $3+$, intense staining. The area of staining was evaluated as follows: 0 , no staining of cells in any microscopic fields; $1+,<30 \%$ of tissue stained positive; $2+, 30-60 \%$ stained positive; $3+,>60 \%$ stained positive. The minimum score when determined (extension + intensity) was, therefore, 0 , and the maximum was 6 . A combined staining score (extension + intensity) of $\leq 2$ was considered to be negative staining (low staining); a score of 3-4 was considered to be moderate staining; and a score of 5-6 was considered to be strong staining.

Western blot analysis. The HCC tissues, corresponding non-tumor normal tissues and QGY cells were lysed in RIPA buffer at $4^{\circ} \mathrm{C}$ for $5 \mathrm{~min}$ (CWbio) and total protein concentration was determined using a Pierce ${ }^{\circledR}$ BCA Protein Assay kit (Thermo Fisher Scientific, Inc.). Extracts containing $50 \mu \mathrm{g}$ protein were separated in $10 \%$ SDS-PAGE gels and electroblotted onto nitrocellulose membranes (HyClone; GE Healthcare Life Sciences). The membranes were blocked using Tris-buffered saline/Tween-20 (25 mM Tris-HCl, $150 \mathrm{mM}$ $\mathrm{NaCl}, \mathrm{pH} 7.5$ and $0.05 \%$ Tween-20) supplemented with 5\% non-fat milk at room temperature for $3 \mathrm{~h}$, followed by overnight incubation at $4^{\circ} \mathrm{C}$ with primary antibodies (rabbit anti-SPAG9 antibody; Abnova, Tapai, Taiwan; cat. no. PAB8794; dilution, 1:500). Following three washes with Tris-buffered saline/Tween-20 (25 mM Tris- $\mathrm{HCl}, 150 \mathrm{mM} \mathrm{NaCl}, \mathrm{pH} 7.5$ and $0.05 \%$ Tween-20), the membranes were incubated with mouse anti-rabbit IgG horseradish peroxidase-conjugated secondary antibodies (cat. no. sc-2491; Santa Cruz Biotechnology, Inc.; dilution, 1:5,000) at room temperature for $1 \mathrm{~h}$ and the specific signals were visualized using an ECL detection system. Anti-GAPDH antibody (Santa Cruz Biotechnology, Inc.; cat. no. Sc-25778; 1:3,000) was used as a loading control at $4^{\circ} \mathrm{C}$ overnight. The bands were analyzed using Gel Automated Digitizing System software (version 4.0; Silk Scientific, Orem, UT, USA). The relative expression levels (fold) were evaluated 
Table I. Characteristics of patients with HCC.

\begin{tabular}{|c|c|c|c|c|}
\hline Samples & Age (years) & Sex & Tumor size $(\mathrm{cm} \mathrm{x} \mathrm{cm} \mathrm{x} \mathrm{cm)}$ & $\begin{array}{l}\text { Pathological diagnosis and classification } \\
\text { (Edmondson grading system) (30) }\end{array}$ \\
\hline 1 & 42 & Male & $5.0 \times 4.0 \times 3.5$ & 2-3 grade well differentiated HCC \\
\hline 2 & 40 & Female & $5.0 \times 5.0 \times 4.5$ & 2 grade moderately differentiated $\mathrm{HCC}$ \\
\hline 3 & 39 & Male & $7.0 \times 5.0 \times 5.0$ & 2 grade moderately differentiated $\mathrm{HCC}$ \\
\hline 4 & 44 & Female & $3.5 \times 3.0 \times 0.5$ & 2-3 grade well differentiated HCC \\
\hline 5 & 45 & Male & $4.0 \times 3.0 \times 3.0$ & 2-3 grade well differentiated $\mathrm{HCC}$ \\
\hline 6 & 48 & Male & $4.0 \times 3.5 \times 2.0$ & 2-3 grade well differentiated $\mathrm{HCC}$ \\
\hline 7 & 58 & Male & $6.0 \times 6.0 \times 4.5$ & 2 grade moderately differentiated $\mathrm{HCC}$ \\
\hline 8 & 56 & Male & $3.0 \times 2.5 \times 2.0$ & 1-2 grade well differentiated HCC \\
\hline 9 & 50 & Male & $3.0 \times 4.0 \times 4.0$ & 2-3 grade well differentiated $\mathrm{HCC}$ \\
\hline 10 & 43 & Male & $3.5 \times 4.0 \times 2.0$ & 2 grade moderately differentiated $\mathrm{HCC}$ \\
\hline 11 & 57 & Female & $5.5 \times 5.0 \times 4.0$ & 1-2 grade well differentiated $\mathrm{HCC}$ \\
\hline 12 & 51 & Male & $3.5 \times 3.0 \times 3.0$ & 2-3 grade well differentiated $\mathrm{HCC}$ \\
\hline 13 & 64 & Male & $6.0 \times 3.5 \times 4.0$ & 2 grade moderately differentiated $\mathrm{HCC}$ \\
\hline 14 & 58 & Female & $5.0 \times 3.5 \times 3.0$ & 2-3 grade well differentiated HCC \\
\hline 15 & 48 & Male & $4.0 \times 5.0 \times 3.5$ & 2 grade moderately differentiated $\mathrm{HCC}$ \\
\hline 16 & 54 & Male & $4.0 \times 3.5 \times 3.0$ & 1-2 grade well differentiated \\
\hline
\end{tabular}

HCC, hepatocellular carcinoma.

by normalizing the integrated optical density (IOD) for each band to that of the corresponding GAPDH band.

Design and synthesis of SPAG9 hairpin-like small interfering (si)RNA, and construction of recombinant eukaryotic expression plasmid. According to the SPAG9 gene sequence (NM_001130527.2), the oligo DNA single strand 1, 2 was designed and synthesized by Ambion; Thermo Fisher Scientific, Inc., and was used as the target of RNAi. The control siRNA oligonucleotides 3 and 4 were also designed and led to the formation of double-stranded DNA with annealed oligonucleotides. EcoRI and BamH RV restriction sites were introduced at the end of the terminal. The lentivirus pWPT-green fluorescent protein (GFP) was used as the carrier; the viral vector was purchased from Clontech Laboratories, Inc. (Mountainview, CA, USA). A lentivirus vector containing GFP, SPAG9 RNAi sequences or control siRNA was constructed: SPAG9 siRNA, TCTGGAAACGACATTTATGG; control siRNA, TGAAGG TCGGAGTCAACGGATT.

siRNA virus infection of QGY cells. QGY HCC cells were cultured in RPMI-1640 medium supplemented with 10\% FBS at $37^{\circ} \mathrm{C}$ in $5 \% \mathrm{CO}_{2}$. There were three groups assessed in the present study: An empty vector group, a control siRNA group and a SPAG9 siRNA group. At $60 \%$ confluence, the lentivirus vector was added at a multiplicity of infection of 10 at $37^{\circ} \mathrm{C}$. Following $48 \mathrm{~h}$, infection efficiency (based on GFP expression level) was determined using an inverted fluorescence microscope (Leica DMl3000B; Leica Microsystems GmbH, Wetzlar, Germany).

Detection of cell growth by MTT. Cells in the logarithmic growth phase were seeded into 96 -well plates at $1 \times 10^{3}$ cells per well in a $200 \mu 1$ volume. A total of $20 \mu 1 \mathrm{MTT}(5 \mathrm{mg} / \mathrm{ml})$ was added to each well and plates were incubated at $37^{\circ} \mathrm{C}$ for $4 \mathrm{~h}$. The liquid was removed from each well and $150 \mu$ l dimethyl sulfoxide was added at $37^{\circ} \mathrm{C}$ for $5 \mathrm{~min}$. Plates were rapidly oscillated at room temperature at $300 \mathrm{x} \mathrm{g}$ on a microplate reader (MK3; Thermo Fisher Scientific, Inc.) for $60 \mathrm{sec}$ to fully dissolve the precipitate, and absorbance of each well at $490 \mathrm{~nm}$ was evaluated.

Cell cycle analysis by flow cytometry. The QGY cells were cultured in serum-free RPMI-1640 medium (Gibco; Thermo Fisher Scientific, Inc.) at $37^{\circ} \mathrm{C}$ in $5 \% \mathrm{CO}_{2}$ for $24 \mathrm{~h}$ and digested with $0.25 \%$ trypsin at room temperature for $2 \mathrm{~min}$, washed once with PBS, centrifuged at $476 \mathrm{x}$ g for $5 \mathrm{~min}$ and resuspended in $70 \%$ ethanol. Cell density was adjusted to $1 \times 10^{6}$ cells $/ \mathrm{ml}$ and cells were fixed with $4 \%$ formaldehyde at $4^{\circ} \mathrm{C}$ overnight. Cells were washed with cold PBS and $100 \mu 1 \mathrm{RNase}$ A $(0.5 \mathrm{mg} / \mathrm{ml})$ was added. After $30 \mathrm{~min}$ at $37^{\circ} \mathrm{C}, 400 \mu \mathrm{l}$ propidium iodide $(10 \mu \mathrm{l} / \mathrm{ml})$ was added and the samples were incubated at $4^{\circ} \mathrm{C}$ in the dark for $30 \mathrm{~min}$. A FACS Canto II flow cytometer (BD Biosciences, Franklin Lakes, NJ, USA) was then used to detect the cell cycle distribution.

Transwell chamber assay to investigate the migration ability of cells. Cells in the logarithmic growth phase were digested with trypsin at room temperature for $2 \mathrm{~min}$. A total of $600 \mu \mathrm{l}$ $10 \%$ FBS supplemented with RPMI-1640 was added to the lower Transwell chamber and $3 \times 10^{5}$ cells in $300 \mu \mathrm{l}$ serum-free medium was added to the upper chamber. Following a $48 \mathrm{~h}$ incubation at $37^{\circ} \mathrm{C}$ in $5 \% \mathrm{CO}_{2}$, the chamber was washed with PBS and a cotton swab was used to remove the cells that did not pass through the basal membrane of the invasion chamber. Cells that had adhered to the surface of the inferior chamber 
A

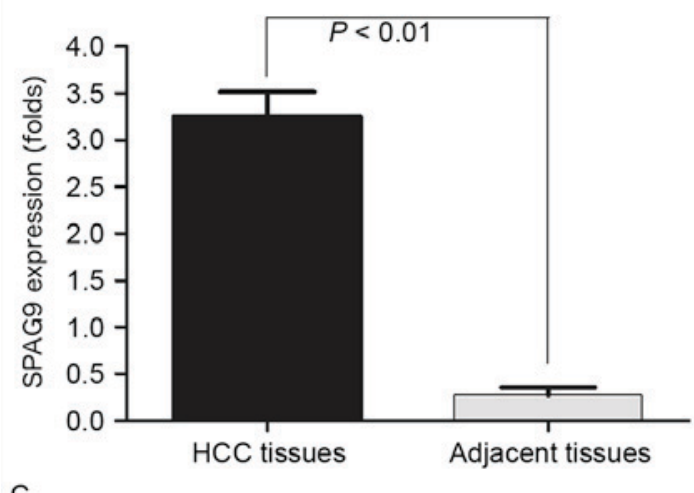

C

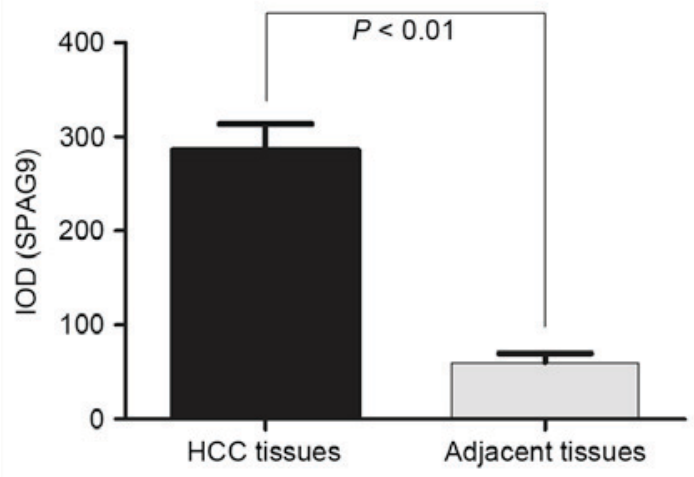

B

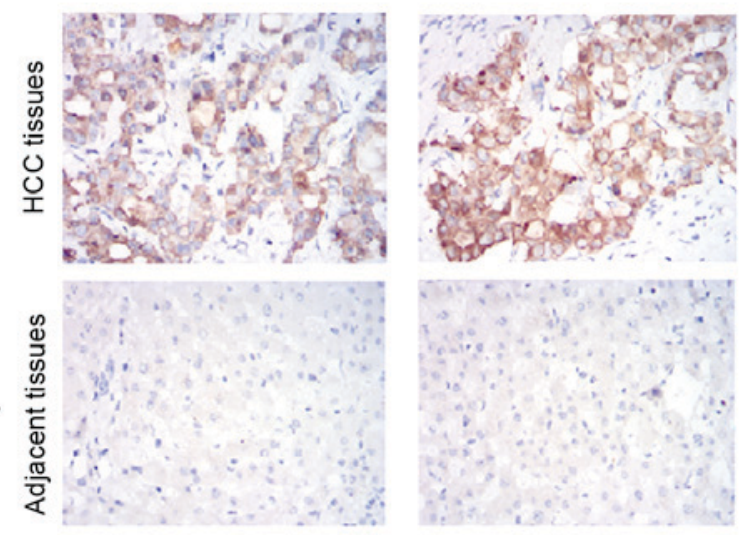

D

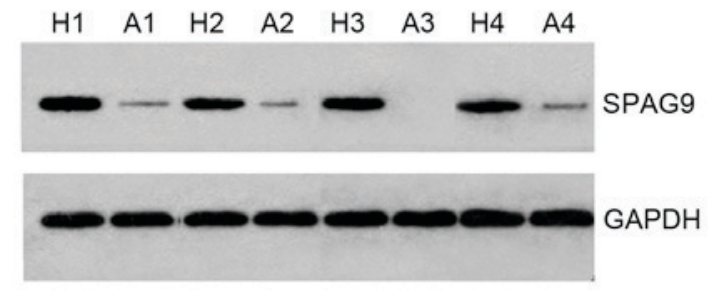

Figure 1. Detection of SPAG9 expression levels in the HCC tissues and the adjacent non-cancerous tissues by RT-qPCR, IHC and western blotting. (A) RT-qPCR was performed to validate the expression level of SPAG9 in HCC tissues and the adjacent non-cancerous tissues. GAPDH was used as an internal control and for normalization of the data. (B) IHC analysis of the expression level of SPAG9 protein in HCC and adjacent non-cancerous tissues. Brown grains indicate a positive signal. Original magnification, $x 400$. (C) The protein expression levels of SPAG9 were significantly higher in the HCC tissues compared with in adjacent non-cancerous tissues, as assessed by western blot analysis. (D) SPAG9 protein expression levels in 4 tissues used in the detection of mRNA expression levels by RT-qPCR. SPAG9, sperm-associated antigen 9; HCC, hepatocellular carcinoma; RT-qPCR, reverse transcription-quantitative polymerase chain reaction; IHC, immunohistochemistry; H, HCC tissues; A, adjacent non-cancerous tissues; IOD, integrated optical density.

were fixed with $100 \%$ methanol at room temperature for $30 \mathrm{~min}$ and the chamber was immersed in Giemsa (Sigma-Aldrich; Merck KGaA, Darmstadt, Germany) staining solution at room temperature for $20 \mathrm{~min}$. Excess dye was removed with PBS and the chambers were dried in air. Various fields of view (magnification, x100) were randomly captured by light microscope (Olympus Corporation) and cells were counted. The number of assessed fields of view was 200 .

Statistical analyses. The Pearson's $\chi^{2}$ test, Fisher's exact test, unpaired Student's t-tests, Wilcoxon signed-rank tests, Mann-Whitney U tests and Kruskal-Wallis one-way analysis of variance tests were performed using SPSS version 18.0 (SPSS, Inc., Chicago, IL, USA). The Bonferroni post hoc test used for the $\chi^{2}$ tests and the Kruskal Wallis tests. Results were expressed as the mean \pm standard deviation. All P-values were two-tailed, and $\mathrm{P}<0.05$ was considered to indicate a statistically significant difference.

\section{Results}

SPAG9 is highly expressed in HCC tissues. In order to detect the mRNA expression levels of SPAG9 in HCC and the adjacent non-cancerous tissues, 16 samples of each were selected to perform RT-qPCR of the SPAG9 gene. The data were analyzed using the $2^{-\Delta \Delta \mathrm{Cq}}$ method and the fold change in the expression levels of these genes relative to the internal control gene, GAPDH, were analyzed. The expression level of the SPAG9 gene was higher in the HCC samples compared with in the adjacent non-cancerous tissues, and the normalized SPAG9 gene expression level in HCC was upregulated by 3.35-fold ( $\mathrm{P}=0.003$; Fig. 1A).

To confirm the pattern of SPAG9 expression in HCC, IHC was performed with antibodies against SPAG9 protein in $\mathrm{HCC}$ and adjacent non-cancerous tissues. SPAG9 was identified as differentially expressed between HCC tissues vs. the adjacent non-cancerous tissues. IHC demonstrated a similar pattern in protein expression level to the western blotting results. There was a $75.0 \%(12 / 16)$ high score of SPAG9 expression level in HCC tissues and $0 \%(0 / 16)$ in the adjacent non-cancerous tissues. The distribution of a low score was $0 \%(0 / 16)$ and $62.5 \%(10 / 16)$ in HCC and the adjacent non-cancerous tissues, respectively $(\mathrm{P}=0.0001$; Fig. $1 \mathrm{~B}$; Table II). This corresponded with the RT-qPCR results.

To determine whether the SPAG9 protein was expressed at a higher level in HCC compared with adjacent non-cancerous tissues, the protein expression levels of SPAG9 were further examined by western blotting in 1 to 4 samples (Fig. 1C and D). SPAG9 protein high expression level was detected in cancerous tissue (IOD 286.84 \pm 75.91 ) and at lower levels in the adjacent noncancerous tissues (IOD 29.86 \pm 34.91 ; P<0.01; Fig. 1C), which corresponded with the RT-qPCR results. 
Table II. Expression levels of SPAG9 in HCC tissues compared with adjacent non-cancerous tissues, as assessed by immunohistochemistry.

\begin{tabular}{|c|c|c|c|c|c|c|}
\hline \multirow[b]{2}{*}{ Tissue } & \multirow[b]{2}{*}{ No. patients } & \multicolumn{3}{|c|}{ Score } & \multirow[b]{2}{*}{$\chi^{2}$} & \multirow[b]{2}{*}{ P-value } \\
\hline & & $\begin{array}{c}\text { Low }(\%) \\
(0-2)\end{array}$ & $\begin{array}{c}\text { Moderate (\%) } \\
\quad(3-4)\end{array}$ & $\begin{array}{l}\text { High }(\%) \\
(5-6)\end{array}$ & & \\
\hline $\mathrm{HCC}$ & 16 & $0(0)$ & $4(25.0)$ & $12(75.0)$ & 22.40 & 0.0001 \\
\hline Adjacent tissues & 16 & $10(62.5)$ & $6(37.5)$ & $0(0)$ & & \\
\hline
\end{tabular}

Pearson's $\chi^{2}$ test was used for statistical analysis. SPAG9, sperm-associated antigen 9; HCC, hepatocellular carcinoma.

Table III. Proliferation of QGY cells.

\begin{tabular}{lcccc}
\hline & \multicolumn{4}{c}{ Incubation period (h) } \\
\cline { 2 - 5 } Group & 24 & 48 & 72 & 96 \\
\hline SPAG9 siRNA & $0.294 \pm 0.007$ & $0.376 \pm 0.021^{\mathrm{a}}$ & $0.584 \pm 0.063^{\mathrm{a}}$ & $0.662 \pm 0.127^{\mathrm{a}}$ \\
Control siRNA & $0.316 \pm 0.031$ & $0.506 \pm 0.063$ & $0.812 \pm 0.064$ & $0.946 \pm 0.127$ \\
Empty vector & $0.294 \pm 0.035$ & $0.518 \pm 0.042$ & $0.825 \pm 0.076$ & $0.982 \pm 0.135$ \\
\hline
\end{tabular}

Proliferation was analyzed using an MTT assay $(\mathrm{n}=10) .{ }^{\text {a }}<0.01$, SPAG9 siRNA vs. control siRNA vector. SPAG9, sperm-associated antigen 9; siRNA, short interfering RNA.

SPAG9 effects the proliferation of HCC cells. QGY human HCC cells were infected with lentiviral vectors engineered to express siRNA targeting SPAG9 or a control siRNA with an empty vector. Green fluorescence due to a virally expressed GFP was observed in cells following infection for $12 \mathrm{~h}$ using an inverted fluorescence microscope. Fluorescence increased with infection time. The same vision field was randomly selected and observed under fluorescence ( 73 perspectives) and white light (76 perspectives) to determine infection efficiency. At $48 \mathrm{~h}$, the infection efficiency was $~ 92 \%$ (Fig. 2A). The expression level of SPAG9 protein in the SPAG9 siRNA cells was significantly lower compared with in cells in the control siRNA group (Fig. 2B). These results revealed that the silencing of SPAG9 expression was successful in QGY cells.

To investigate the effect of silencing of SPAG9, the present study evaluated the proliferation of QGC cells between the siRNA group and control group by MTT assay. The results demonstrated that SPAG9-deficient cells did not proliferate as well as cells treated with empty vector or cells that expressed the control siRNA (Table III). Compared with the control siRNA-expressing cells, proliferation of cells that expressed SPAG9 siRNA were inhibited by $32.6 \%$ at $96 \mathrm{~h}$.

SPAG9 promotes cell cycle progression. Flow cytometry was performed to detect the cell cycle distributions of QGY cells (Fig. 3). In cells that expressed control siRNA, $41.6 \%$ were in the $\mathrm{G}_{0} / \mathrm{G}_{1}$ cell cycle phase, whereas $58.7 \%$ of cells that expressed the SPAG9 siRNA were in the $\mathrm{G}_{0} / \mathrm{G}_{1}$ cell cycle phase. Compared with the control siRNA-treated cells, the percentage of cells
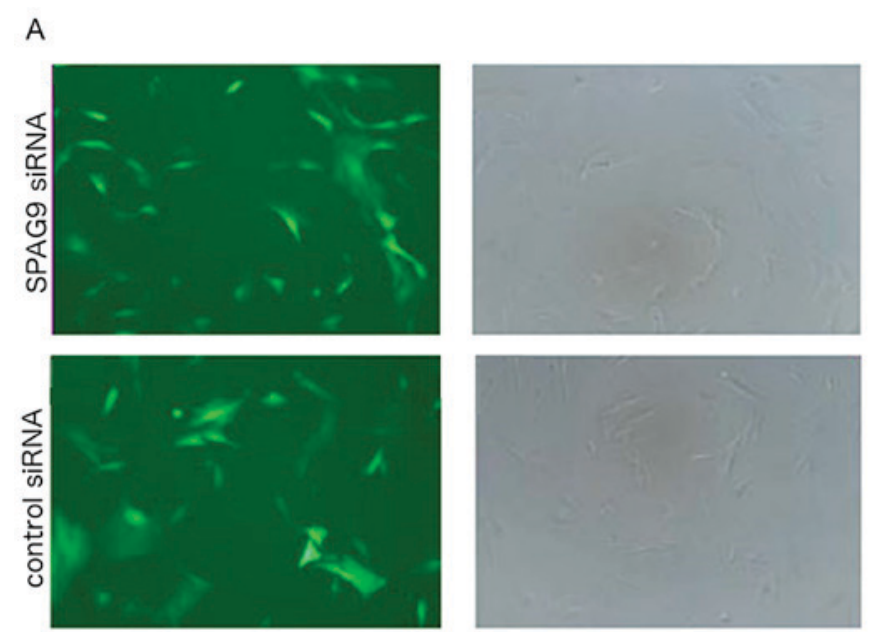

B

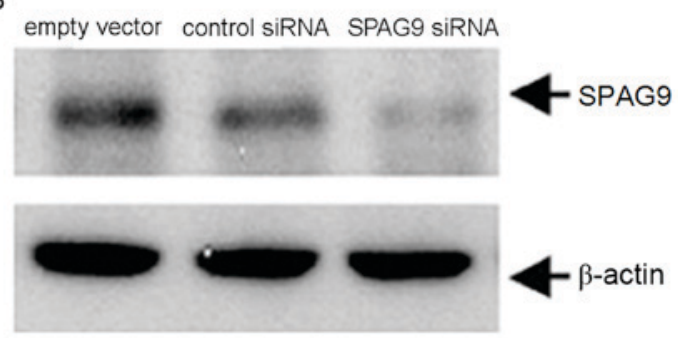

Figure 2. Microscopic analysis of QGY cells $48 \mathrm{~h}$ following infection with lentivirus designed to express SPAG9 siRNA or control siRNA (magnification, x100). (A) Fluorescence and white light images of QGY cells that express SPAG9 siRNA or control siRNA. SPAG9 protein expression levels were analyzed by (B) western blotting in QGY cells infected with an empty vector or vectors containing control siRNA or SPAG9 siRNA. SPAG9, sperm-associated antigen 9; siRNA, small interfering RNA. 

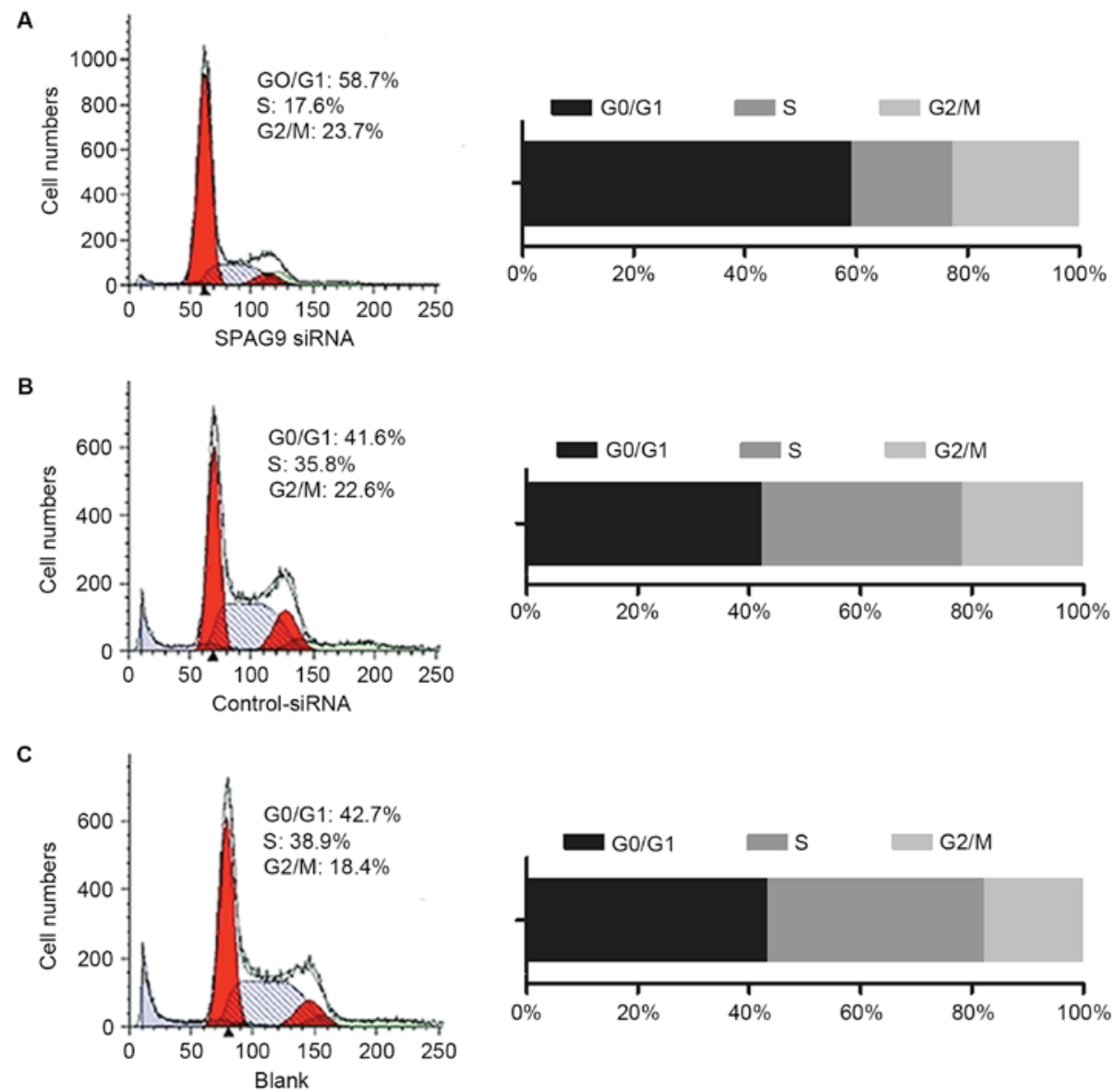

Figure 3. Flow cytometry analysis of the cell cycle in QGY cells infected with (A) lentivirus for expression of SPAG9 siRNA, (B) lentivirus for expression of control siRNA and (C) empty vectors. SPAG9, sperm-associated antigen 9; siRNA, small interfering RNA.

in $\mathrm{G}_{0} / \mathrm{G}_{1}$ cell cycle phase were increased by $17.1 \%$ in SPAG9 siRNA-expressing cells and the percentage in the $\mathrm{S}$ phase was reduced by $18.2 \%$ (Fig. 3). There was no significant difference between cells that expressed control siRNA and cells infected with the empty vector, suggesting that inhibition of SPAG9 expression may inhibit the cell cycle in the $\mathrm{G}_{1}$ and $\mathrm{G}_{2}$ phases.

SPAG9 enhances cell migration. Finally, the migration of cells deficient in SPAG9 was compared with that of control cells using a Transwell chamber assay. Compared with cells that expressed control siRNA, the percentage of cells that expressed the SPAG9 siRNA that migrated toward rich medium was significantly decreased $(\mathrm{P}<0.01)$. There was no difference in migration of cells that expressed control siRNA and cells infected with an empty vector ( $\mathrm{P}>0.05$; Fig. 4$)$. The results of the present study indicated that inhibiting SPAG9 expression levels reduced cell migration.

\section{Discussion}

The occurrence and development of HCC are complex processes associated with a variety of oncogenes, tumor suppressor genes and certain cell cycle regulation factors $(24,25)$. Therefore, further investigation is required to fully understand and improve treatments for HCC. Attempts to diagnose HCC early in order to decrease the mortality rate and prolong the survival time and quality of life have been made (26); however, there have

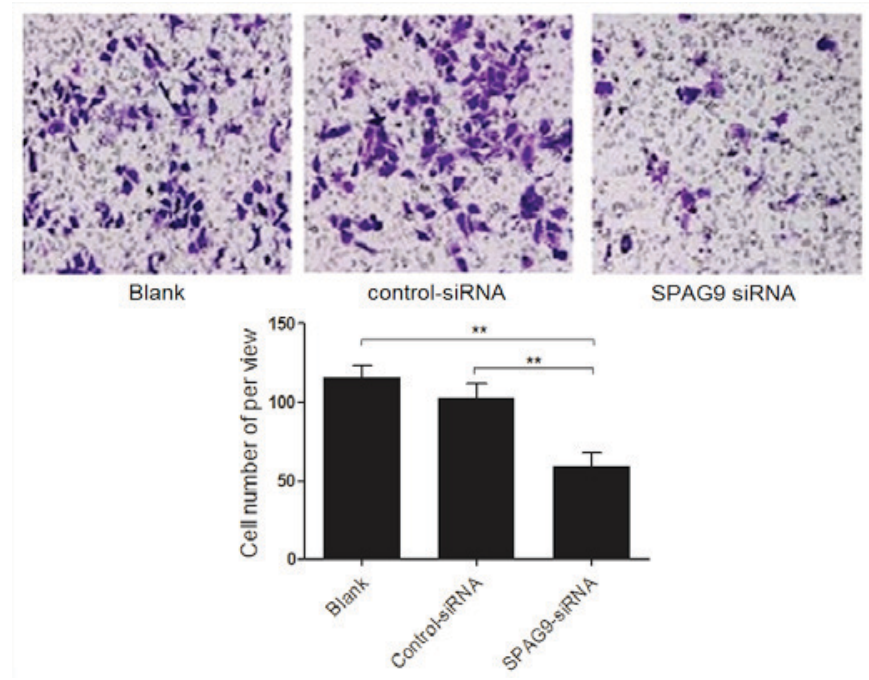

Figure 4. Results of the Transwell chamber assay. Compared with cells that expressed control siRNA and blank cells, the percentage of cells that expressed the SPAG9 siRNA that migrated toward rich medium was significantly decreased $\left({ }^{* *} \mathrm{P}<0.01\right)$. There was no significant difference in migration of cells infected with control siRNA compared with cells infected with empty vector $(\mathrm{P}>0.05)$. SPAG9, sperm-associated antigen 9; siRNA, small interfering RNA.

been no major breakthroughs at present. Cancer/testis antigens expressed in a variety of human malignant tissues provide a 
novel direction for the study of HCC, and SPAG9 is one of these cancer/testis antigens (27). A previous study concerning ovarian cancer suggested that SPAG9 regulates the MAPK signaling pathway (28). The MAPK signaling pathway is mediated by various stimuli, and the selectivity and specificity of these reactions depends on scaffold proteins (29). SPAG9 interacts with JNK in the A549 lung cancer cell line and SPAG9 contributes to invasive abilities via a mechanism mediated by matrix metalloproteinase 9 and the activation of JNK (14).

The present study revealed that the expression level of the SPAG9 gene and protein was upregulated in the HCC tumor tissues compared with in adjacent non-cancerous tissues $(\mathrm{P}<0.01)$. The analysis of HCC tissues from patients in the present study was consistent with previous studies that evaluated SPAG9 expression levels in the QGY hepatoma cell line $(11,27)$. RNAi technology was used to inhibit the expression level of SPAG9 in cultured cells and the results revealed that SPAG9 deficiency was able to affect the proliferation and progression of HCC QGY cells. The present study performed an MTT assay and demonstrated that, compared with the control siRNA-expressing cells, proliferation of cells that expressed SPAG9 siRNA was significantly inhibited from $48 \mathrm{~h}$ and the rate of inhibition achieved was $32.6 \%$ at $96 \mathrm{~h}$. The number of QGY cells in the $G_{0}$ phase increased and the number in the $S$ phase decreased following SPAG9 gene silencing. A Transwell chamber assay was performed and revealed that inhibiting the expression level of SPAG9 reduced the migratory ability of QGY cells; however, the specific mechanism underlying this effect requires further study. Inhibiting SPAG9 expression may effectively decrease the differentiation and proliferation of OGY cells, indicating that SPAG9 may serve a specific function in accelerating the cell cycle, promoting proliferation and migration of HCC. This revealed that downregulation of scaffold proteins may induce inactivation of numerous signaling pathways. Therefore, blocking the tumor signaling pathway by knocking out the tumor scaffold proteins is a novel concept for cancer treatment.

The present study evaluated a limited number of patients and only one immortalized cell line. Due to the heterogeneities of HCC, the expression levels of SPAG9 may differ. SPAG9 protein levels were increased in the adjacent tissues of patients 4 and 7 relative to the adjacent tissues, as assessed by western blotting and IHC, but in the other patients the expression level was low relative to that of the tumor tissues. The present study observed an increased expression level of SPAG9 in the tumor samples evaluated compared with adjacent non-cancerous samples and SPAG9 expression was decreased in adjacent non-cancerous samples compared with tumor samples. The results of the present study suggested that SPAG9 was upregulated in $\mathrm{HCC}$ and may serve an important function in cancer cell proliferation, differentiation and invasion. Furthermore, that downregulation of SPAG9 expression levels may inhibit the proliferation and invasion of HCC. Whether SPAG9 is a potential diagnostic marker and therapeutic target of human $\mathrm{HCC}$ requires additional investigation.

\section{Acknowledgements}

The present study was supported by the Hunan Provincial Health Department Foundation (grant no. B2011-099) and the
Key Project of Hunan Provincial Second People's Hospital Fund Foundation (grant no. 2013-1).

\section{References}

1. Li H, Peng Y, Niu H, Wu B, Zhang Y, Zhang Y, Bai X and He P: SPAG9 is overexpressed in human prostate cancer and promotes cancer cell proliferation. Tumour Biol 35: 6949-6954, 2014

2. Kanojia D, Garg M, Gupta S, Gupta A and Suri A Sperm-associated antigen 9 is a novel biomarker for colorectal cancer and is involved in tumor growth and tumorigenicity. Am J Pathol 178: 1009-1020, 2011.

3. Peng JR, Chen HS, Mou DC, Cao J, Cong X, Qin LL, Wei L, Leng XS, Wang Y and Chen WF: Expression of cancer/testis (CT) antigens in Chinese hepatocellular carcinoma and its correlation with clinical parameters. Cancer Lett 219: 223-232, 2005.

4. Yang P, Huo Z, Liao H and Zhou Q: Cancer/testis antigens trigger epithelial-mesenchymal transition and genesis of cancer stem-like cells. Curr Pharm Des 21: 1292-1300, 2015.

5. Garg M, Chaurasiya D, Rana R, Jagadish N, Kanojia D, Dudha N, Kamran N, Salhan S, Bhatnagar A, Suri S, et al: Sperm-associated antigen 9, a novel cancer testis antigen, is a potential target for immunotherapy in epithelial ovarian cancer. Clin Cancer Res 13: 1421-1428, 2007.

6. Garg M, Kanojia D, Khosla A, Dudha N, Sati S, Chaurasiya D, Jagadish N, Seth A, Kumar R, Gupta S, et al: Sperm-associated antigen 9 is associated with tumor growth, migration, and invasion in renal cell carcinoma. Cancer Res 68: 8240-8248, 2008.

7. Garg M, Kanojia D, Salhan S, Suri S, Gupta A, Lohiya NK and Suri A: Sperm-associated antigen 9 is a biomarker for early cervical carcinoma. Cancer 115: 2671-2683, 2009.

8. Garg M, Kanojia D, Suri S, Gupta S, Gupta A and Suri A: Sperm-associated antigen 9: A novel diagnostic marker for thyroid cancer. J Clin Endocrinol Metab 94: 4613-4618, 2009.

9. Kanojia D, Garg M, Gupta S, Gupta A and Suri A: Sperm-associated antigen 9, a novel biomarker for early detection of breast cancer. Cancer Epidemiol Biomarkers Prev 18: 630-639, 2009.

10. Yu P, Yan L, Zhang H, Lin X and Zhao X: Expression and clinical significance of sperm-associated antigen 9 in patients with endometrial carcinoma. Int J Gynecol Cancer 22: 87-93, 2012.

11. Garg M, Kanojia D, Suri S and Suri A: Small interfering RNA-mediated down-regulation of SPAG9 inhibits cervical tumor growth. Cancer 115: 5688-5699, 2009.

12. Sinha A, Agarwal S, Parashar D, Verma A, Saini S, Jagadish N, Ansari AS, Lohiya NK and Suri A: Down regulation of SPAG9 reduces growth and invasive potential of triple-negative breast cancer cells: Possible implications in targeted therapy. J Exp Clin Cancer Res 32: 69, 2013.

13. Yi F, Ni W, Liu W, Pan X, Han X, Yang L, Kong X, Ma R and Chang R: SPAG9 is overexpressed in human astrocytoma and promotes cell proliferation and invasion. Tumour Biol 34: 2849-2855, 2013.

14. Wang Y, Dong Q, Miao Y, Fu L, Lin X and Wang E: Clinical significance and biological roles of SPAG9 overexpression in non-small cell lung cancer. Lung Cancer 81: 266-272, 2013.

15. Kanojia D, Garg M, Saini S, Agarwal S, Parashar D, Jagadish N, Seth A, Bhatnagar A, Gupta A, Kumar R, et al: Sperm associated antigen 9 plays an important role in bladder transitional cell carcinoma. PLoS One 8: e81348, 2013.

16. Agarwal S, Parashar D, Gupta N, Jagadish N, Thakar A, Suri V, Kumar R, Gupta A, Ansari AS, Lohiya NK and Suri A: Sperm associated antigen 9 (SPAG9) expression and humoral response in benign and malignant salivary gland tumors. Oncoimmunology 3: e974382, 2014.

17. Ferlay J, Shin HR, Bray F, Forman D, Mathers C and Parkin DM: Estimates of worldwide burden of cancer in 2008: GLOBOCAN 2008. Int J Cancer 127: 2893-2917, 2010.

18. Nordenstedt H, White DL and El-Serag HB: The changing pattern of epidemiology in hepatocellular carcinoma. Dig Liver Dis 42 (Suppl 3): S206-S214, 2010.

19. Li P, Cao Y, Li Y, Zhou L, Liu X and Geng M: Expression of Wnt-5a and $\beta$-catenin in primary hepatocellular carcinoma. Int $\mathrm{J}$ Clin Exp Pathol 7: 3190-3195, 2014.

20. Gauglhofer C, Paur J, Schrottmaier WC, Wingelhofer B, Huber D, Naegelen I, Pirker C, Mohr T, Heinzle C, Holzmann K, et al: Fibroblast growth factor receptor 4: A putative key driver for the aggressive phenotype of hepatocellular carcinoma. Carcinogenesis 35: 2331-2338, 2014. 
21. Chu R, Mo G, Duan Z, Huang M, Chang J, Li X and Liu P miRNAs affect the development of hepatocellular carcinoma via dysregulation of their biogenesis and expression. Cell Commun Signal 12: 45, 2014.

22. Xu WH, Zhang JB, Dang Z, Li X, Zhou T, Liu J, Wang DS, Song WJ and Dou KF: Long non-coding RNA URHC regulates cell proliferation and apoptosis via ZAK through the ERK/MAPK signaling pathway in hepatocellular carcinoma. Int J Biol Sci 10: 664-676, 2014.

23. Kanojia D, Garg M, Gupta S, Gupta A and Suri A: Sperm-associated antigen 9, a novel biomarker for early detection of breast cancer. Cancer Epidemiol Biomarkers Prev 18 630-639, 2009

24. Yang H, Xiong FX, Lin M, Yang Y, Nie X and Zhou RL: LAPTM4B-35 overexpression is a risk factor for tumor recurrence and poor prognosis in hepatocellular carcinoma. J Cancer Res Clin Oncol 136: 275-281, 2010.

25. Zhao ZK, Dong P, Gu J, Chen L, Zhuang M, Lu WJ, Wang DR and Liu YB: Overexpression of LSD1 in hepatocellular carcinoma: A latent target for the diagnosis and therapy of hepatoma. Tumour Biol 34: 173-180, 2013.
26. Marquardt JU, Galle PR and Teufel A: Molecular diagnosis and therapy of hepatocellular carcinoma (HCC): An emerging field for advanced technologies. J Hepatol 56: 267-275, 2012.

27. Xie C, Fu L, Liu N and Li Q: Overexpression of SPAG9 correlates with poor prognosis and tumor progression in hepatocellular carcinoma. Tumour Biol 35: 7685-7691, 2014.

28. Ha JH, Yan M, Gomathinayagam R, Jayaraman M, Husain S, Liu J, Mukherjee P, Reddy EP, Song YS and Dhanasekaran DN: Aberrant expression of JNK-associated leucine-zipper protein, JLP, promotes accelerated growth of ovarian cancer. Oncotarget 7: 72845-72859, 2016.

29. Jagadish N, Rana R, Mishra D, Kumar M and Suri A: Sperm associated antigen 9 (SPAG9): A new member of c-Jun NH2 -terminal kinase (JNK) interacting protein exclusively expressed in testis. Keio J Med 54: 66-71, 2005.

30. Edmondson HA and Steiner PE: Primary carcinoma of the liver: A study of 100 cases among 48,900 necropsies. Cancer 7: 462-503, 1954. 